\title{
Zirconia implant abutments: A review
}

\author{
Ana-Luísa Gomes ${ }^{1}$, Javier Montero ${ }^{2}$ \\ ${ }^{1}$ Postgraduate in Dentistry. Department of Surgery. University of Salamanca. Spain \\ ${ }^{2}$ Tenured Lecture Professor in Prosthodontics. Department of Surgery. University of Salamanca. Spain
}

Correspondence:

Department of Surgery.

University of Salamanca.

C/ Alfonso X el Sabio. S/N

Campus Unamuno.

37007. Salamanca. Spain.

javimont@usal.es

Received: $21-12-2009$

Accepted: 23-04-2010

\author{
Gomes AL, Montero J. Zirconia implant abutments: A review. Med Oral \\ Patol Oral Cir Bucal. 2011 Jan 1;16 (1):e50-5. \\ http://www.medicinaoral.com/medoralfree01/v16i1/medoralv16ilp50.pdf \\ Article Number: $16951 \quad$ http://www.medicinaoral.com \\ (C) Medicina Oral S. L. C.I.F. B 96689336 - pISSN 1698-4447 - eISSN: 1698-6946 \\ eMail: medicina@medicinaoral.com \\ Indexed in: \\ Science Citation Index Expanded \\ Journal Citation Reports \\ Index Medicus, MEDLINE, PubMed \\ Scopus, Embase and Emcare \\ Indice Médico Español
}

\begin{abstract}
Objectives: An increasing aesthetic demand within developed populations conducted to the fabrication of metalfree restorations and to a wide use of ceramic materials, due to its excellent characteristics of biocompatibility and aesthetics. With the incessant increase of commercial labels involved in this technological advance, a review is imposed on ceramic abutments, specifically on zirconia. We made a search of articles of peer-reviewed Journals in PubMed/ Medline, crossing the terms "Dental Abutments", "Dental Porcelain" and "Zirconia". The review was divided by subtopics: zirconia physical and mechanical properties, precision fit in the implant-abutment interface, zirconia abutments strength and, finally, bacterial adherence and tissues response. Several studies demonstrate that zirconia abutments offer good results at all the levels but relevant issues need further studies and evaluation. One of the most important is the clinical long term success of zirconia abutments on implants, given that in the literature there are no sufficient in vivo studies that prove it.
\end{abstract}

Key words: Zirconia, dental ceramics, implant abutment.

\section{Introduction}

The anterior sector rehabilitation with dental implants is a clinical challenge. One of the most challenging scenarios for the dental practitioner is to give answer to the patient expectations with a good result of the implant integration and excellent esthetical crown incorporation in the dental arch.

The use of osteo-integrated dental implants, with an history of confirmed success and long term following of the patient, propelled dentistry to a new era that involve more and more clinicians and investigators interested all over the world. A high esthetical demand lead to the fabrication of metal free restorations that allow better results in aesthetically compromised areas. Ceramic materials are being highly used in Odontology due to its ideal properties of biocompatibility and aesthetics. Since there is a never-ending increase in the number of enterprises that develop zirconia abutments, but the scientific studies valuing its clinical success are rare, this review is relevant to access the state-of-art.

\section{Material and Methods}

A bibliographic review was made in peer-reviewed journals in PubMed /Medline. Initially a simple search was made with the keywords "zirconia implant abutment", which was lengthened with the sequence: 
"Dental abutments" [Mesh] AND "Dental Porcelain" [Mesh] AND zirconia. The publication period was the last twenty years and only articles in English were considered. A review of related articles was also made, selecting the articles considered of interest within the previously chosen manuscripts. Within the search results, the articles were divided by subtopics: zirconia physical and mechanical properties, precision fit in the implant/ abutment interface and finally, bacterial adherence and tissue response to zirconia abutments.

\section{Results}

In the first search the results were insufficient, only 8 articles in peer-reviewed journals in PubMed, so we made a new search crossing Mesh terms and reviewing some related articles. The results of this search were 20 articles that included bibliographic reviews, in vitro and in vivo studies and case reports. The most relevant contributions of these studies are presented in Tables 1 and 2 .

\section{Discussion}

Historically implant abutments were manufactured in metal. To fulfil the esthetical demand of dentists and patients, pre-fabricated or custom abutments of different metals were designed. The use of titanium abutments prevents the occurrence of galvanic and corrosive reactions in the implant/abutment interface, which enhances the peri-implant soft tissues health due also to its high biocompatibility. However, excessive oxidation of titanium at ceramic melting temperatures and the low adhesion of the oxides to the surface of this material may be a problem in the titanium/porcelain systems. Metal abutments only solve partially the esthetical, functional and hygienic questions fundamental to the restorations over implants success (1).

The soft tissue discoloration in the cervical third of the implant anterior portion of the restorations can result in the visibility, by transparency, of the abutment material over the implant. The presence of a greyish gum can be due to a thin gingival tissue around the abutment which cannot block the reflected light from the metallic abut-

Table 1. Summary of the most relevant studies reviewed.

\begin{tabular}{|c|c|c|}
\hline $\begin{array}{l}\text { AUTHORS } \\
\text { AND YEAR }\end{array}$ & TYPE OF STUDY & CONCLUSIONS \\
\hline Piconi and Maccauro, 1999 (10) & Review & $\begin{array}{l}\text { Review about zirconia biophysical and biomechanical } \\
\text { properties, giving relevance to its biocompatibility. }\end{array}$ \\
\hline Manicone et al, 2007 (11) & Review & $\begin{array}{l}\text { Different uses of zirconia as a material used in Odontol- } \\
\text { ogy due to its properties. }\end{array}$ \\
\hline Andersson et al, 1999 (5) & $\mathrm{PS}^{1}$ and $\mathrm{CS}^{2}$ in vivo & $\begin{array}{l}\text { There was a good cumulative survival rate of the zir- } \\
\text { conia abutments. Bone loss was higher in the titanium } \\
\text { abutments than when using the Zirconia ones. }\end{array}$ \\
\hline Andersson et al, 2003 (6) & PS and CS in vivo & $\begin{array}{l}\text { Good results, stable aesthetical and functionally using } \\
\text { abutments CerAdapt, can be obtained in the support of } \\
\text { small bridges. }\end{array}$ \\
\hline Glauser et al, 2004 (14) & PS in vivo & $\begin{array}{l}\text { During } 4 \text { years there were no fracture of the experimen- } \\
\text { tal zirconia abutments used in the study. }\end{array}$ \\
\hline Vigolo et al, 2006 (13) & $\mathrm{CS}$ in vitro & $\begin{array}{l}\text { All the tested groups had satisfactory results concerning } \\
\text { the adaptation in the interface implant/abutment. } \\
\text { The best values were obtained in the titanium and zirco- } \\
\text { nia groups. }\end{array}$ \\
\hline Yildirim et al, 2003(7) & CS in vivo & $\begin{array}{l}\text { Zirconia ceramic abutments withstood fracture loads } \\
\text { more than twice as higher as those recorded for Alu- } \\
\text { mina ones. }\end{array}$ \\
\hline Att et al, 2006 (3) & $\mathrm{CS}$ in vitro & $\begin{array}{l}\text { With a similar method of the study above mentioned } \\
\text { from Yildirim et al ( } 7 \text { ) the results were very different, } \\
\text { probably due to the artificial aging of the specimens. }\end{array}$ \\
\hline Gehrke et al, 2006(18) & $\mathrm{CS}$ in vitro & $\begin{array}{l}\text { Loosening torque registered only slightly decrease af- } \\
\text { ter the } 80000 \text { loading cycles in the zirconia abutments } \\
\text { tested. }\end{array}$ \\
\hline Scarano et al, 2004(20) & \multirow{2}{*}{ In vivo and in vitro studies } & \multirow{2}{*}{$\begin{array}{l}\text { Zirconia accumulates less quantity of bacterial plaque } \\
\text { than titanium; this colonization is also less pathogenical } \\
\text { in the zirconia disc. }\end{array}$} \\
\hline Rimondini et al, 2002(19) & & \\
\hline
\end{tabular}

1 Prospective Study

2 Comparative Study 


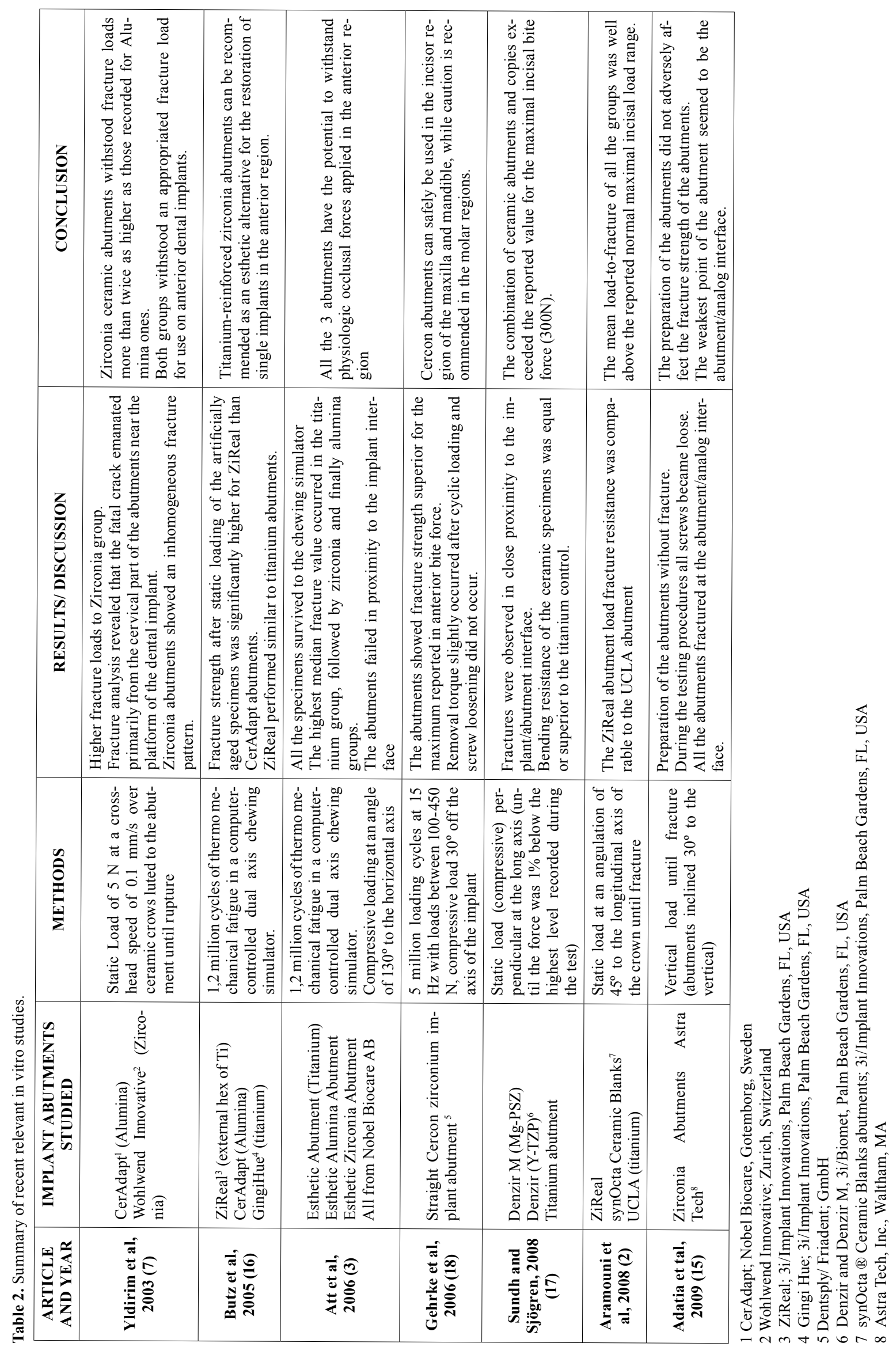


ment (2-4). The fabrication of ceramic abutments was developed to overcome this limitation of conventional abutments.

Due to the zirconia mechanical properties it was suggested its use as implant abutments. The first ceramic abutments were the CerAdapt ${ }^{\mathrm{TM}}$ (Nobel Biocare, Goteborg, Sweden) made of alumina and designed to fit the extern hexagon of Brånemark implant type (5).

Andersson et al in 1999 (5) evaluated the short and long term clinical function of CerAdapt ${ }^{\mathrm{TM}}$ abutments. They inserted 105 implants in 32 patients of 3 clinics. After two years, the cumulative survival rate was of $97.1 \%$ for the implants, and $97.2 \%$ for the restorations over the implants $(94.7 \%$ for ceramic abutments and $100 \%$ for titanium abutments). In all the cases the peri-implant mucosa was stable; nevertheless there was a higher loss of marginal bone around the titanium abutments $(0.4$ $\mathrm{mm})$ than around the ceramic ones $(0.2 \mathrm{~mm})$. The authors found that the results were encouraging for the use of ceramic abutments.

In 2003, the results of the long term study showed that in 5 years, the cumulative rate of success was of $97.2 \%$ ( $94.7 \%$ for ceramic abutments and $100 \%$ for the titanium abutments) (6). The authors concluded that the ceramic abutments CerAdapt ${ }^{\mathrm{TM}}$ had liable results aesthetical and functionally to support short span fixed prostheses.

A recent in vitro investigation (7) studied the fracture strength of alumina and zirconia abutments restored with ceramic crowns (IPS Empress). Although both resist the values established in the literature as maximum load in the incisal bite $(90-370 \mathrm{~N})$, the zirconia abutments results were more than twice than the alumina abutments strength (7). The use of zirconia abutments is well documented in the literature with several case reports of its clinical success $(8,9)$. Zirconia mechanical properties are the best ever reported for dental ceramics. This can allow the production of posterior fixed partial dentures (FPD) and a decrease of the thickness of the crown core.

\section{- Physical and Mechanical properties of zirconia}

Zirconia is a polymorphic crystal that can be found in 3 crystallographic forms: monoclinic (M), cubic (C) and tetragonal (T). The zirconia is monoclinic at room temperature, being stable till $1170^{\circ} \mathrm{C}$, above this temperature it becomes tetragonal and, over $2370^{\circ} \mathrm{C}$, passes to the cubic phase, this is stable until the melting point at $2380^{\circ} \mathrm{C}$ is reached (10). During cooling, a tetragonal-monoclinic (T-M) transformation takes place in a temperature range of about $100^{\circ} \mathrm{C}$ below $1070^{\circ} \mathrm{C}$. This transformation phase is associated to a volume expansion of about 3-4 \%. The stress generated in the expansion originates fractures that after sinterization (between $1500-1700^{\circ} \mathrm{C}$ ) are able of break in peaces the zirconia at room temperature $(10,11)$.

The addiction of stabilizing doping agents like $\mathrm{CaO}$,
$\mathrm{MgO}, \mathrm{CeO}$ and $\mathrm{Y} 2 \mathrm{O} 3$ to the pure zirconia allows the production of multiphase materials known as Partially Stabilized Zirconia (PSZ) which microstructure consists generally, at room temperature, in a cubic zirconia matrix with tetragonal and monoclinic zirconia precipitates in a minor phase (10).

Garvie et al in 1975, reviewed by Manicone (11), demonstrated how to obtain the better phase transformation in PSZ, improving zirconia mechanical strength and toughness. They observed that tetragonal metastable precipitates finely dispersed within the cubic matrix were able to be transformed into the monoclinic phase, when the constraint exerted on them by the matrix was relieved, that is by a crack advancing in the material. In that case, the stress field associated with expansion due to the phase transformation acts in opposition to the stress fields that promotes the propagation of the crack. An enhancement in toughness is obtained, because the energy associated with crack propagation is dissipated, both in the tetragonal-monoclinic transformation and in overcoming the compression stresses due to the volume expansion. The authors stabilized zirconia with $8 \%$ mol of $\mathrm{MgO}$. In this model, where the zirconia properties were rationalized, the authors mention this material as "ceramic steel".

PSZ can be obtained with the system ZrO2-Y2O3 or with $\mathrm{ZrO} 2-\mathrm{CeO}$, in this system is possible to do ceramics, at room temperature, with only tetragonal phase called TZP (tetragonal zirconia polycrystals). Both systems are abbreviated to Y-TZP and Ce-TZP respectively (11).

This material with 2-3\% mol Y2O3 (3Y-TZP), is composed by tetragonal grains sized in nanometres. Above a critical grain size, the 3Y-TZP is less stable and more favourable to the spontaneous transformation T-M, so to a smaller grain size $(<1 \mu \mathrm{m})$ is associated a smaller rate of transformation. The tetragonal phase, at room temperature, depends in grain size, yttrium content and the compression of the matrix around the grains, conditioning, in this way the mechanical properties of the TZP (10).

\section{- Precision fit in the interface Implant/ Abutment}

The adjustment between implants and the implant-supported prosthesis has been described as a relevant factor in stress transference, biological answer of peri-implant tissues and in complications of the prosthetic restoration. The adjustment between the external hexagon of implant and the internal hexagon of the abutment will have to allow less than $5^{\circ}$ of rotational movement to maintain the screw union stable, this value was established by Binon in 1996 and reviewed by Garine et al in 2007 (12).

The vertical or horizontal misalignment applies extra loads to the different restoration components, to the implant and to the bone causing: loosening of the prosthe- 
sis retention, abutment fractures, bone microfractures, lost of crestal bone and osteointegration lost.

Vigolo et al in 2006 (13) studied the rotational freedom of Procera abutments made in different materials: titanium, alumina and zirconia. The values registered for the three types of abutments were consistently demonstrated as inferior to $3^{\circ}$. Nevertheless, the groups of titanium and zirconia did not have significant differences, being their values significantly inferior to those of the group of the alumina abutments (13).

In 2007, Garine et al (12) analyzed the rotational misalignment between abutments and implants. All the groups obtained values inferior to $5^{\circ}$ and significantly different average values among them. The groups of totally ceramic abutments had a superior rotational misalignment when compared with the ceramic abutments with a metallic ring (12).

Finally, there are also authors who consider that the zirconia abutments can be the cause of wearing down and abrasion of the connection metallic part, thus, as a result of positioning/removal of the zirconia abutments during their individualization, we can originate smoothing of the corners of the external hexagon, for example (6).

\section{- Zirconia abutments strength}

In order to consider them as a viable alternative, the ceramic abutments must display mechanical and biological qualities identical or superior to those of universally used titanium abutments. The strength values of the abutments will have to be superior to the registered maximum values for the anterior sector that can fluctuate between $90-370 \mathrm{~N}$. In a prospective study of 4 years, with experimental zirconia abutments placed directly on an implant of external hexagon, abutments fractures were not registered (14).

In 2003, Yildirim et al. (7) studied the fracture resistance of different materials abutments covered by Empress Crowns, when subjected to static loads. They registered that zirconia abutments obtained values more than twice higher than the alumina ones. Both materials revealed a resistance able to bear incisal forces documented in the literature.

Att et al (3), in a similar study, achieved disrupting results with the study of Yildirim et al (7). They found a similar strength between zirconia and alumina abutments. Authors justify their results with the fact that, in this study, the abutments were subjected to artificial aging. Both studies previously mentioned, consider the cervical part of the abutment as the higher stress concentration area after the torque generated by the screwing $(3,7)$.

In a recent study, Adatia et al. (15) proceeded with an in vitro study to assess the effect of different degrees of zirconia abutments clinical reduction, and their resistance to fracture, submitted to clinical similar conditions. When original zirconia abutments (without clinical reduction) were tested, they fractured in the cervical region, such as stated in other studies $(3,7)$, in the adjacent region to the gold screw and the platform of the implant, for all this the design of the interface implant/ pillar seems to have a main paper in the fracture mode $(7,15)$. The zirconia abutments registered values of strength at least $15 \%$ higher than the anterior bite force, and it was checked that the abutments preparation did not affect adversely their resistance to the fracture (15). In Butz et al work (16), was compared the fracture strength, rate of survival and way of failure of the ceramic abutments. The authors concluded that after being under the mastication simulator and static loads, the strength of the zirconia abutments was comparable to those of titanium $(281 \mathrm{~N}$ versus $305 \mathrm{~N})(2,16)$, being the rate of fracture also similar to the titanium abutments one. Thus, the authors recommend zirconia abutments as an alternative for restoration of unitary implant rehabilitations in the anterior region.

Sundh and Sjögren in 2008 (17) studied the flexion strength of the zirconia abutments when is used a cantilever structure. The results demonstrate that the flexion strength of the zirconia abutments is greater or similar to the titanium abutments that were the control group (17).

According to Gehrke et al (18) the zirconia abutments under static load exhibited maximum fracture values of $672 \mathrm{~N}$, being manifestly smaller $(269 \mathrm{~N})$ after 80000 cycles, supporting loads that exceed the established maximum values of force at incisal level. In addition loosening torque was evaluated, that decreased very slightly at the end of the cycles and the total loosening was not observed (18).

In conclusion, the majority of the studies consider that the ceramic abutments failure is more frequent in the cervical region, very close to the interface implant/abutment $(2,3,15-17)$.

- Bacterial adherence and response of the tissues

Dental implants require a biological sealing to inhibit the epithelial recession and the bacterial invasion of the sub-epithelial conjunctive tissue and of implant interfaces. It was emphasized the need of promoting the formation of an adhered gingival tissue to create a biological barrier to the bacterium migration and toxins to the biological space (19).

Zirconia is a biocompatible material that has optimal aesthetic and mechanical properties (10). The properties related to the biocompatibility of the zirconia are even better than those of titanium.

The bacterial adhesion, which is important in the maintaining of zirconia restorations without periodontal problems, was proven satisfactorily low $(19,20)$.

Scarano et al (20) registered a degree of bacterial coating of $12.1 \%$ in the zirconia, compared to $19.3 \%$ in the titanium. Rimondini et al (19) confirmed these results with an in vivo study in which crystals of Y-TZP accu- 
mulated fewer bacteria than titanium, in terms of total number of bacteria, but also considering their potential pathogenicity.

The protective barrier of adhered gum around the transmucosal abutments requires a nontoxic material and that enhances the adhesion and the growth of surrounding tissues. Different ideas like changing the zirconia surface topography or emergence profile had outcome in the scientific community, needing to be deeply stu-died.

\section{Conclusions}

Although zirconia abutments presented values of fracture strength not as good as conventional titanium abutments they are indicated in aesthetically compromised areas. On the other hand these abutments revealed a good adjustment in the interface with dental implants, excellent biocompatibility and good aesthetical appearance, especially in patients with unitary rehabilitations over implants with a thin gingival biotype.

Thereby several aspects remain to be studied and assessed, on top of all the long term clinical success of ceramic restorations on implants with zirconia abutments, once in the literature there are not enough in vivo studies that prove it.

\section{References References with links to Crossref-DOI}

1. Prestipino V, Ingber A. All-ceramic implant abutments: esthetic indications. J Esthet Dent. 1996;8:255-62.

2. Aramouni P, Zebouni E, Tashkandi E, Dib S, Salameh Z, Almas $\mathrm{K}$. Fracture resistance and failure location of zirconium and metallic implant abutments. J Contemp Dent Pract. 2008;9:41-8.

3. Att W, Kurun S, Gerds T, Strub JR. Fracture resistance of singletooth implant-supported all-ceramic restorations: an in vitro study. J Prosthet Dent. 2006;95:111-6.

4. Yildirim M, Edelhoff D, Hanisch O, Spiekermann H. Ceramic abutments--a new era in achieving optimal esthetics in implant dentistry. Int J Periodontics Restorative Dent. 2000;20:81-91.

5. Andersson B, Schärer P, Simion M, Bergström C. Ceramic implant abutments used for short-span fixed partial dentures: a prospective 2-year multicenter study. Int J Prosthodont. 1999;12:318-24.

6. Andersson B, Glauser R, Maglione M, Taylor A. Ceramic implant abutments for short-span FPDs: a prospective 5-year multicenter study. Int J Prosthodont. 2003;16:640-6.

7. Yildirim M, Fischer H, Marx R, Edelhoff D. In vivo fracture resistance of implant-supported all-ceramic restorations. J Prosthet Dent. 2003;90:325-31.

8. Román-Rodríguez JL, Roig-Vanaclocha A, Fons-Font A, GranellRuiz M, Solá-Ruiz MF, Bruguera-Alvarez A. Full maxillary rehabilitation with an all-ceramic system. Med Oral Patol Oral Cir Bucal. 2010;15:e523-5.

9. Kollar A, Huber S, Mericske E, Mericske-Stern R. Zirconia for teeth and implants: a case series. Int J Periodontics Restorative Dent. 2008;28:479-87.

10. Piconi C, Maccauro G. Zirconia as a ceramic biomaterial. Biomaterials. 1999;20:1-25.

11. Manicone PF, Rossi Iommetti P, Raffaelli L. An overview of zirconia ceramics: basic properties and clinical applications. J Dent. 2007;35:819-26.

12. Garine WN, Funkenbusch PD, Ercoli C, Wodenscheck J, Murphy WC. Measurement of the rotational misfit and implant-abutment gap of all-ceramic abutments. Int J Oral Maxillofac Implants. 2007;22:928-38
13. Vigolo P, Fonzi F, Majzoub Z, Cordioli G. An in vitro evaluation of titanium, zirconia, and alumina procera abutments with hexagonal connection. Int J Oral Maxillofac Implants. 2006;21:575-80.

14. Glauser R, Sailer I, Wohlwend A, Studer S, Schibli M, Schärer P. Experimental zirconia abutments for implant-supported singletooth restorations in esthetically demanding regions: 4-year results of a prospective clinical study. Int J Prosthodont. 2004;17:285-90.

15. Adatia ND, Bayne SC, Cooper LF, Thompson JY. Fracture resistance of yttria-stabilized zirconia dental implant abutments. J Prosthodont. 2009;18:17-22.

16. Butz F, Heydecke G, Okutan M, Strub JR. Survival rate, fracture strength and failure mode of ceramic implant abutments after chewing simulation. J Oral Rehabil. 2005;32:838-43.

17. Sundh A, Sjögren G. A study of the bending resistance of implantsupported reinforced alumina and machined zirconia abutments and copies. Dent Mater. 2008;24:611-7.

18. Gehrke P, Dhom G, Brunner J, Wolf D, Degidi M, Piattelli A. Zirconium implant abutments: fracture strength and influence of cyclic loading on retaining-screw loosening. Quintessence Int. 2006;37:1926.

19. Rimondini L, Cerroni L, Carrassi A, Torricelli P. Bacterial colonization of zirconia ceramic surfaces: an in vitro and in vivo study. Int J Oral Maxillofac Implants. 2002;17:793-8.

20. Scarano A, Piattelli M, Caputi S, Favero GA, Piattelli A. Bacterial adhesion on commercially pure titanium and zirconium oxide disks: an in vivo human study. J Periodontol. 2004;75:292-6. 